\title{
Metacognição e as relações com o saber
}

\section{Metacognition and relationships with knowledge}

\author{
Nancy Nazareth Gatzke Corrêa ${ }^{1}$ \\ https:// orcid.org/0000-0002-8160-1849 \\ Marinez Meneghello Passos ${ }^{2}$ \\ https://orcid.org/0000-0001-8856-5521 \\ Sergio de Mello Arruda ${ }^{2}$ \\ https://orcid.org/0000-0002-4149-2182
}

Resumo: Neste artigo trazemos os resultados de uma investigação que analisou os processos metacognitivos de estudantes de Física do Ensino Médio por meio das relações com o saber. Os dados foram coletados por meio de entrevistas e, posteriormente, submetidos aos procedimentos da Análise Textual Discursiva. As percepções dos estudantes sobre seu processo da aprendizagem foram analisadas com base em três novas categorias metacognitivas, denominadas de epistêmicas, pessoais e sociais. Com isso foi possível afirmar que o saber, o sentir e o valorar estão relacionados ao processo metacognitivo e que o planejamento das ações voltadas para a aprendizagem, seu monitoramento e avaliação, é realimentado pelas emoções e reflexões dos estudantes, as quais emergem do contato com o outro e com o mundo.

Palavras-chave: Ensino de física. Ensino médio. Aprendizagem. Metacognição.

\begin{abstract}
We present the results of an investigation that analyzed the metacognitive processes of learning Physics for High School students. Metacognition here is treated as relationships with knowledge. The data were collected through interviews and later submitted to Discursive Textual Analysis procedures. The students' perceptions about their learning process were analyzed by means of three new metacognitive categories, called epistemic, personal and social. With this, it was possible to affirm that knowing, feeling and valuing are related to the metacognitive process and that the planning of actions focused on learning, its monitoring and evaluation is influenced by the emotions and reflections of the students which emerge from contact with others and with the world.
\end{abstract}

Keywords: Physics teaching. High school. Learning. Metacognition.

\footnotetext{
${ }^{1}$ Colégio Elo, Jacarezinho, PR, Brasil. E-mail: <nancyngatzke@gmail.com>.

${ }^{2}$ Universidade Estadual de Londrina (UEL), Londrina, PR, Brasil.
} 


\title{
Introdução
}

A palavra "aprender", na contemporaneidade, carrega a ideia de adquirir e acumular, sendo tratada, segundo Tunes e Bartholo (2009), como um processo de aquisição e acúmulo gradual de informação, conhecimento ou experiência relacionada à noção de quantidade. Todavia, perdura um sentido de aprender como abertura à renovação, na acepção do aprender como busca, como uma necessidade de indagação: por quê, para que e o que se busca, apresentando-se como um processo qualitativo e não quantitativo, sendo esse considerado um acontecimento da relação do aprendiz com o mundo, por meio das interações.

\begin{abstract}
Visto dessa ótica, o aprender é próprio da nossa condição no mundo: algo que nos é dado como possibilidade. Desde o nascimento até o dia final, enquanto houver vida, a possibilidade está posta, mas jamais imposta. Ela pode ser recusada pelo nosso fechamento ao encontro do mundo. No decorrer da vida, alternando-se os modos de aprender e os seus mecanismos. Contudo, não se trata aqui de uma deterioração, mas de formas peculiares de refração daquilo que parte do mundo para o homem e do homem para o mundo e que são referidas à natureza da nossa vida social de relação (TUNES; BARTHOLO, 2009, p. 28).
\end{abstract}

Para ampliar a compreensão do conceito de aprendizagem nas suas mais diversas abordagens e construções teóricas, trazemos também a definição de Illeris (2013) em que a aprendizagem é assumida como qualquer processo que proporcione alguma mudança permanente nas capacidades do sujeito que não seja exclusivamente o amadurecimento biológico ou o envelhecimento. $\mathrm{O}$ autor ainda chama a atenção para as condições de integração do indivíduo com o ambiente social, cultural ou material em um processo psicológico interno de elaboração e aquisição. Essa compreensão abrangente e extrapola a natureza do próprio processo de aprendizagem, incluindo todas as condições que influenciam e são influenciadas por esse processo.

Illeris (2013) inclui condições internas e externas, relacionadas à aprendizagem em si, com seus processos, dimensões, tipos, obstáculos e possíveis aplicações. As condições internas de aprendizagem são definidas por "características do aprendiz que influenciam as possibilidades de aprendizagem e estão envolvidas nos processos referentes a ela” e as condições externas são aceitas como "aspectos situados fora do indivíduo que influenciam as possibilidades e estão envolvidos nos processos de aprendizagem” (ILLERIS, 2013, p. 27). Ambas levando em consideração os aspectos relacionados aos "espaços de aprendizagem”, e as diversas condições relacionadas à cultura e à sociedade.

Dando continuidade à nossa busca por elucidar o que compreendemos por aprendizagem, seguimos com Charlot (2000) e sua afirmação de que a aprendizagem envolve a conexão de um novo saber a um saber já existente ou como este se complementa a partir de alguma ideia, que ainda não compõe um saber. Ele também esclarece que esse saber pode ser atualizado, reelaborado ou abandonado, dependendo da produção de sentido do indivíduo, sendo esse sentido físico: como tato, paladar, olfato, visão, gustação, ou mental, como a construção de imagens mentais que se integram para que a aprendizagem ocorra.

Para esse mesmo autor aprender pode ser adquirir um saber, um conteúdo intelectual ou dominar um objeto ou atividade. Ele esclarece que aprender não se refere a processos 
idênticos que podem ser reproduzidos quando necessário, mas está relacionado a exercer uma atividade em situação, ou seja, o momento, o tempo em que acontece, o lugar onde acontece e com quem essa aprendizagem acontece, concluindo que "todo ser humano aprende, pois se não aprendesse, não se tornaria humano" (CHARLOT, 2000 p. 65).

Aprender, então, é dominar uma relação, uma relação identitária, uma relação com o outro além de uma relação epistêmica, fato que amplia o sentido do aprender (colocando-o além do saber), pois muitas "coisas" e de naturezas diversas podem ser aprendidas, como um saber com o sentido estrito de um conteúdo intelectual, dominando um objeto, uma atividade como aprender a falar, dirigir, cozinhar, por exemplo, ou formas relacionais (a convivência em distintos grupos sociais), considerando, além da dimensão do sujeito que busca o saber, outras intimamente imbricadas, como a relação de identidade e a social.

De acordo com o autor, "não há saber senão para um sujeito engajado em uma certa relação com o saber” (CHARLOT, 2000, p. 61) e este saber se constrói mediante uma história coletiva que é a da mente humana e das atividades do homem e está submetido a processos coletivos de validação, acúmulo e transmissão.

Charlot (2000, p. 61) distingue informação, conhecimento e saber da seguinte forma: “a informação" é um dado exterior ao sujeito, é objetiva, podendo ser armazenada e transmitida a outros; "O conhecimento" é subjetivo, resulta de uma experiência pessoal e é intransmissível, e "o saber" compartilha dessas duas características: é uma informação da qual o sujeito se apropria, e quando é produzido pelo indivíduo pode se tornar passível de ser comunicado, pois este produto pode estar disponível para que qualquer indivíduo o acesse. O valor e o sentido do saber surgem das relações induzidas e pensadas por sua apropriação, sendo, portanto, o saber, uma relação.

As definições de relação com o saber foram construídas ao longo de uma década (1982-1992), e ainda são colocadas por Charlot (2000) como em processo de construção, no qual apresenta a relação com o saber, ultrapassando os saberes escolares, contemplada de forma ampla. Um processo em que se busca criar uma rede de conceitos pela inserção da relação com o saber definido da seguinte forma:

A relação com o saber é a relação com o mundo, com o outro e com ele mesmo, de um sujeito confrontado com a necessidade de aprender; a relação com o saber ser um conjunto (organizado) das relações que um sujeito mantém com tudo quanto estiver relacionado com "o aprender" e o "saber"; [...] a relação com o saber é o conjunto das relações que um sujeito mantém com um "conteúdo de pensamento", uma atividade, uma relação interpessoal, um lugar, uma pessoa, uma situação (CHARLOT, 2000, p. 80-81).

A ênfase do conceito de relação com o saber, nesse sentido amplo, está colocada justamente na noção de relação: uma forma de relação entre o sujeito com o mundo, com ele mesmo e com os outros, que se caracteriza por ser, ao mesmo tempo, simbólica, ativa e temporal, definindo-acomo "A relação com o saber é relação com o tempo. A apropriação do mundo, a construção de si mesmo, a inscrição em uma rede de relações com os outros 'o aprender"' (CHARLOT, 2000, p. 78).

A relação epistêmica de apropriação é a relação com um saber objeto, que assume sua forma por meio da linguagem escrita, pois sua existência independe do sujeito, ou objetiva- 
ção, quando essa aprendizagem epistêmica se faz com o sujeito consciente dessa apropriação. Aprender também pode ser o domínio de uma atividade ou a capacidade de utilizar um objeto que está engajado no mundo. O sujeito epistêmico, nesse caso, não é o eu reflexivo, mas o eu que está imerso na situação. Ou ainda, pode-se aprender um dispositivo relacional, que aqui significa ser capaz de regular a relação consigo próprio por meio da relação com os outros e vice-versa em uma relação situacional.

Aprender a dominar uma relação é "tornar-se capaz de regular essa relação e encontrar a distância conveniente entre si e os outros, entre si e si mesmo, e isso, em situação" (CHARLOT, 2000, p. 70). Toda relação com o saber é uma relação consigo por meio da aprendizagem - uma relação identitária - fazendo referência à "construção de si e seu eco reflexivo, a imagem de si” (CHARLOT, 2000, p. 70). Há um exemplo relatado pelo autor, em que o sujeito tem consciência de que o sucesso escolar reflete segurança e, em contrapartida, o fracasso escolar produz prejuízos na relação consigo, pois a sociedade moderna impõe o sucesso escolar como sendo uma passagem obrigatória, para se tornar "alguém".

A dimensão social não se acrescenta às dimensões epistêmicas e identitárias, ela corrobora para produzir uma dimensão completa da aprendizagem. Aprender, então, no que diz respeito à relação social, é ocupar-se de um mundo preexistente, de histórias sociais marcadas pelos encontros, desejos, aspirações e rupturas, não somente de posições e trajetórias compreendidas como passagem entre posições.

O aprender não está relacionado apenas enquanto meio de acesso a uma ou outra posição social no mundo, mas à maneira de apropriar-se desse mundo. Para Charlot (2000, p. 57), o sujeito é "um ser humano levado pelo desejo e aberto para um mundo social no qual ele ocupa uma posição e do qual é elemento ativo" e complementa: a relação com o saber está intimamente relacionada ao desejo de aprender, colocando em evidência o valor do que se aprende.

O aprendizado, nesta pesquisa, sinaliza para o processo de construção do conhecimento, superando os reducionismos cognitivos, compreendendo o caráter social e cultural presente nas bases do pensamento, e esse como elaboração intrínseca à produção de emoções, que envolve e desencadeia todo o processo de aprendizagem. Para essa construção é necessária uma apropriação do que se aprende, por meio da recriação crítica e reflexiva do conhecimento que se dá na emergência do sujeito que aprende como elemento ativo e indispensável a esse processo.

Após esses esclarecimentos a respeito do que compreendemos por aprendizagem e relações com o saber, descrevemos o que Arruda, Lima e Passos (2011, p. 145-146) assumem por dimensões epistêmicas, pessoais e sociais, que nesta pesquisa foram consideradas como categorias a priori, para a acomodação dos excertos identificados nos relatos dos depoentes participantes desta investigação.

A. A relação epistêmica com o saber: diz respeito à relação com o saber enquanto um objeto do mundo a ser apropriado e compreendido; um saber dotado de objetividade, consistência e estrutura independentes; um saber "existente em si mesmo", "depositado em objetos, locais e pessoas" e imerso em um "universo de saberes distinto do mundo da ação, das percepções e das emoções" (CHARLOT, 2000, p. 69).

B. A relação pessoal com o saber: diz respeito à "relação de identidade com o saber"; o saber enquanto objeto que faz sentido, que é parte da história 
pessoal do sujeito, de sua vida e de suas expectativas; é o saber enquanto objeto de desejo, de interesse; o saber que o sujeito "gosta" e que o faz mobilizar-se à sua procura. (CHARLOT, 2000, p. 72).

C. A relação social com o saber: diz respeito ao fato de que o sujeito nasce inscrito em um espaço social, ocupando uma posição social objetiva, que lhe definem o contexto inicial em que ele vai se relacionar com o saber; nesse meio o saber possui valores dados pela comunidade em que o sujeito vive, recebendo o impacto das expectativas e aspirações de outros com relação a ele (CHARLOT, 2000, p. 73).

Naquela ocasião os autores concluíram que, partindo dessas categorias de análise (e de outros desdobramentos interpretativos possibilitados por elas), é possível reconhecer a incidência das principais reflexões, preocupações e opiniões do professor com relação à ação, à docência, e passaram a aplicá-las em diferentes contextos de pesquisa. Desta forma, ampliaram-se as abordagens sobre as configurações de aprendizagem que, nessa perspectiva, podem ser tratadas como lugares de aprendizagem.

$\mathrm{Na}$ busca pela ampliação da reflexão acerca da aprendizagem dos estudantes em sala de aula e, também, em outras fontes, encontrou-se a possibilidade de analisar essas relações, extrapolando a conotação epistêmica da aprendizagem e aproximando-a da relação com o sentir e a valoração que cada aprendiz impõe à sua própria aprendizagem. Foi por esses motivos que nos propusemos a investigar: quais percepções e reflexões no processo metacognitivo do aprender podem ser evidenciadas na aprendizagem de Física pelos estudantes de Ensino Médio?

A seguir discorremos sobre metacognição.

\section{Metacognição}

O termo "metacognição" foi introduzido sob a influência das pesquisas da psicologia cognitiva iniciadas por Flavell (1971). Após inúmeros estudos Flavell pôde afirmar que existe a relação dos processos mentais da memória com a cognição, o que demonstra que o indivíduo deve evoluir a partir da infância, apresentando grande mudança no seu comportamento de memória relevante ao conhecimento conceitual e suas habilidades cognitivas, pois a mente humana sabe mais e pensa melhor à medida que envelhece, e, essas mudanças, no que diz respeito ao que o sujeito sabe e como pensa, têm efeitos sobre o que aprende e lembra-se, como aprende e lembra-se, e, ainda, quando deve aprender e lembrar. Outro ponto importante está no fato de que uma tarefa de memória depende da natureza da tarefa em particular e de experiências anteriores que a pessoa apresenta com as respectivas tarefas de memória, bem como seu nível de competência cognitiva.

Os fatores ou variáveis referentes à pessoa, à tarefa e à estratégia (FLAVELL; WELLMAN, 1975) e as relações estabelecidas entre essas variáveis são frutos da construção do conhecimento que o estudante tem sobre ele mesmo, que é estabelecido com a tomada de consciência das próprias variáveis, bem como pelo modo como interage e influencia a aprendizagem.

A variável pessoa, segundo Flavell e Wellman (1975), é concebida pelas convicções que os estudantes apresentam sobre si e em comparação com os outros, tratando-se de um fator pessoal. Pode ser entendida como a percepção do funcionamento do pensamento, no que tange 
o pensar universal, ou intraindividual, quando são identificadas as características pessoais que auxiliam na aprendizagem, como o estudante se relaciona com determinado conteúdo e quais são suas afinidades. E, ainda, interindividual, na comparação com as características pessoais e de seus pares. $\mathrm{O}$ estudante consegue reconhecer as características da cognição presentes nele próprio ou no outro e o reconhecimento de como se processam as informações na sua mente e na do outro, quando percebe que ele não consegue, mas que o outro consegue e vice-versa.

O conhecimento da variável tarefa por Flavell e Wellman (1975) está sujeito ao tipo de atividade proposta, sua abrangência e nível de exigência. Dependendo da natureza da informação e da exigência da tarefa é que o estudante vai avaliar como deve proceder para realizá-la e se vai realizá-la. Essa decisão envolve os conhecimentos de fatores pessoais que, neste momento, estão entrelaçados nas variáveis da pessoa e da tarefa, demonstrando que essas variáveis relacionam-se.

Sobre os conhecimentos das estratégias, Flavell e Wellman (1975) afirmam que para desenvolvê-las o estudante precisa envolver-se intensamente com sua aprendizagem. Nesse momento, são necessárias conexões que extrapolam a metacognição e a cognição, tais como a afetividade, o lugar, o instante, o tempo disponível para a realização, a razão de realizar determinada tarefa, entre outras.

A identificação da estratégia a ser utilizada e o reconhecimento de que é necessário utilizar uma estratégia, envolve um pensamento metacognitivo, uma reflexão acerca do processo, da estrutura que deverá ser envolvida para ter êxito na realização da atividade (FLAVELL; WELLMAN, 1975).

Assim como a metacognição desempenha um papel importante na cognição social e nos diversos tipos de automonitoramento, Flavell (1979) demonstra que existem indicações claras de que o pensamento metacognitivo começa a fazer contato com as áreas da teoria da aprendizagem social e da modificação do comportamento cognitivo relacionadas ao desenvolvimento da personalidade e ao aprimoramento da aprendizagem.

Por fim, reproduzindo Peterson, Baker e McGaw (2010, p. 204), quando afirmam que o termo "metacognição" significa literalmente "pensar sobre o pensamento" e assumindo a metacognição como um processo em que ocorre a tomada de consciência, com monitoramento, avaliação e autorregulação da aprendizagem; que o caráter epistêmico está intrinsecamente atrelado aos processos que envolvem o conhecimento cognitivo e metacognitivo da memória, seus processos e sua relação com objetos, pessoas e locais, de forma a possibilitar ou contribuir para a ocorrência da aprendizagem de um determinado conteúdo; que a dimensão pessoal é o saber enquanto objeto de desejo, de interesse, portanto, a reflexão sobre a aprendizagem a respeito do que o sujeito gosta de aprender, de acordo com as características da sua identidade relacionadas à aprendizagem de determinado conteúdo; que os valores estabelecidos pela sociedade à qual o aprendiz pertence, tanto para se estabelecer um envolvimento com o outro, no que diz respeito a conversas, interações com professores, tutores, amigos e familiares, como também para estabelecer seu lugar na sociedade, no que se refere à escolha profissional, e todos os requisitos que esta escolha envolve, torna-se possível evidenciar percepções epistêmicas, pessoais e sociais nas relações estabelecidas com o saber. 


\section{Procedimentos metodológicos}

Nesta seção apresentamos os encaminhamentos metodológicos que sustentaram o desenvolvimento desta pesquisa, considerando o contexto investigado, as definições de entrevista narrativa e reflexiva (que nos permitiu adotar a entrevista coletiva) e os procedimentos da Análise Textual Discursiva (ATD). (MORAES; GALLIAZI, 2011).

Fizemos uso de entrevista ${ }^{4}$ gravada em áudio que foi transcrita e revisada pelos próprios entrevistados, que as complementaram com diversos comentários e autorização de uso. Tais complementações ocorreram por meio de registros via $W h a t s A p p^{5}$, no telefone celular, ou Facebook ${ }^{6}$ via internet (no computador).

Nossa intenção, nesta investigação, era que o estudante narrasse seus processos mentais de aprendizagem, aproximando-se assim da proposta de entrevista narrativa, apresentada por Flick (2009): a entrevista narrativa é uma opção interessante frente a outras formas de entrevista, por fornecer detalhes contextuais e relações necessárias para aprofundar a compreensão da história, enriquecendo os relatos, principalmente de eventos ou de experiências.

Porém, ao elaborar a pergunta geradora e realizar as primeiras tomadas de dados, verificou-se a necessidade de repensar a forma de abordar e encaminhar a entrevista. Foi então que a entrevista reflexiva surgiu como uma alternativa interessante, devido à sua natureza reflexiva e pelo fato de preservar as características da narrativa.

Para Szymanski, Almeida e Prandini (2008), a entrevista reflexiva constitui um momento de construção de um novo conhecimento, que permeia os limites da representatividade da fala e da horizontalidade das relações de poder, em um encontro interpessoal, repleto de subjetividade tanto pelo entrevistado como pelo entrevistador.

O que trazemos neste artigo são os resultados obtidos de uma entrevista coletiva ${ }^{7}$ em que as principais tarefas do entrevistador foram impedir que participantes individuais dominassem a fala com suas contribuições e estimular os indivíduos reservados a emitirem opiniões, tentando obter respostas de todo o grupo. A questão geradora que nos acompanhou em todas as coletas foi: “Como você percebe sua aprendizagem?”, propiciando aos estudantes que narrassem sua forma de aprender. Aos poucos, o direcionamento para a aprendizagem em Física aconteceu,

\footnotetext{
${ }^{4}$ Em todo o desenvolvimento da pesquisa, realizamos inúmeras entrevistas, que foram organizadas e analisadas. Neste artigo optamos por trazer os resultados de uma delas, que julgamos ser representativa de todas, indicando que as conclusões dos casos aqui não apresentados não são divergentes.

${ }^{5}$ WhatsApp é um aplicativo de celular que permite a troca de mensagens escritas.

${ }^{6}$ Facebook é uma rede social utilizada para interagir por meio de trocas de mensagens.

${ }^{7}$ A entrevista coletiva, com característica de narrativa, é utilizada como uma forma de apresentar experiências cada vez mais analisadas na psicologia, pois permite ao pesquisador abordar o mundo empírico do entrevistado de um modo abrangente. Essa entrevista é iniciada com a utilização de uma "pergunta gerativa de narrativa" que se refere ao tópico de estudo e que tem por finalidade estimular o entrevistado, seguindo por aprofundar e completar sempre que não se esgotem os detalhamentos, finalizando com a "fase do equilíbrio" na qual o entrevistado é considerado como especialista e teórico de si. (FLICK, 2009).
} 
com a inferência de novas perguntas, quando se apresentava silêncio demonstrando o esgotamento do assunto. Entre elas destacamos: "Como percebe que aprendeu algum conteúdo de Física?"; "Você percebeu se aprendeu o conteúdo estudado na última aula?"

Juntamente à introdução dessas novas questões, buscou-se realizar sínteses, de tempos em tempos, apresentando a compreensão do entrevistador diante da fala do entrevistado, mantendo-se a postura descritiva e utilizando do mesmo vocabulário mencionado pelo depoente. Introduziu-se, também, a estratégia de estabelecer vínculos entre as questões, nos momentos em que foi necessário criar a possibilidade de um aprofundamento na reflexão e expressão por parte do entrevistado, ou a focalização no objetivo proposto inicialmente, quando os depoentes afastavam-se, demasiadamente, do tema.

Para a organização dos registros foi realizada a desmontagem dos textos, fragmentando-os para atingir as unidades de análise, seguida pelo estabelecimento das relações com a categorização em busca da captação do novo emergente; comunicado na forma do metatexto, em um processo auto-organizado, em que os resultados originais não podem ser previstos (todos esses procedimentos pautados na ATD).

Para iniciar o processo de análise textual, foi realizada a transcrição da entrevista, e enviada para que os estudantes realizassem o processo de validação e complementação. Após receber os retornos, iniciamos um processo de sistematização e identificação, em que pinçamos os trechos considerados relevantes para esta investigação e, assim, foi constituído o corpus da pesquisa:

\footnotetext{
Os textos não carregam um significado a ser apenas identificado, trazem significantes exigindo que o leitor ou pesquisador construa significados a partir de suas teorias e pontos de vista. Isso requer que o pesquisador em seu trabalho se assuma como autor das interpretações que constrói a partir dos textos que analisa. Naturalmente nesse exercício hermenêutico de interpretação é preciso ter sempre em mente o outro polo, o autor do texto original (MORAES; GALIAZZI, 2011, p. 17).
}

Para estruturar a análise foram elencadas as categorias estabelecidas a priori, a partir da fundamentação teórica das relações com o saber: epistêmicas, pessoais e sociais, tendo sempre em mente a busca pelos excertos que trouxessem a percepção e reflexão dos estudantes acerca dos processos metacognitivos da aprendizagem de Física. Por isso, ao realizar a leitura e desmontagem do corpus, procurou-se selecionar os trechos que permitissem capturar essa percepção ou apontassem indícios da reflexão de cada um sobre seus processos de aprendizagem.

\section{Apresentação e análise dos dados}

Nos Quadros 1, 2 e 3 exemplificamos a organização e sistematização dos dados interpretados (pois a completude das análises e acomodações não seria possível apresentar em um artigo) de acordo com os referenciais teóricos adotados e os procedimentos analíticos assumidos.

Como é possível observar nas colunas 1 dos Quadros temos as indicações Epistêmicas, Pessoais e Sociais, nossas categorias a priori. Na coluna 2 - denominada por 'metas/ações 
cognitivas’ - temos algumas subdivisões. Esclarecemos que elas foram necessárias por conta das definições estabelecidas pelos referenciais relativos à aprendizagem e à metacognição descritos anteriormente (de forma resumida) neste artigo. Ainda nesta coluna dos Quadros, optamos por trazer exemplos dos excertos acomodados em cada subdivisão a fim de elucidar os leitores quanto ao que alocamos em cada uma delas. Nos excertos temos partes sublinhadas e negritadas, isso foi realizado para deixar em destaque os fragmentos relacionados com a descrição inicial de cada subdivisão. Os estudantes que participaram ativamente da entrevista coletiva foram identificados pelas letras MB, I, G, F, L, AJ, e Nt. O número que antecede o excerto está relacionado à ordem crescente em que esses fragmentos estão localizados na transcrição da entrevista; os complementos entre parênteses foram inseridos pelos autores, a fim de tornar o excerto compreensível, em função da fragmentação realizada ou da omissão de expressões pelo próprio depoente; há em alguns momentos a inserção de uma letra "w", o que indica que esta informação foi inserida após o dia da entrevista.

Posteriormente à apresentação de cada um dos Quadros 1, 2 e 3 (com as categorias estabelecidas a priori: Epistêmica, Pessoal e Social) traremos algumas intervenções analíticas e, após essas intervenções, dois gráficos que retratam os resultados.

Quadro 1. Categoria epistêmica e metas/ações cognitivas

\begin{tabular}{|c|c|}
\hline Categoria & Metas/ações cognitivas \\
\hline \multirow{4}{*}{ 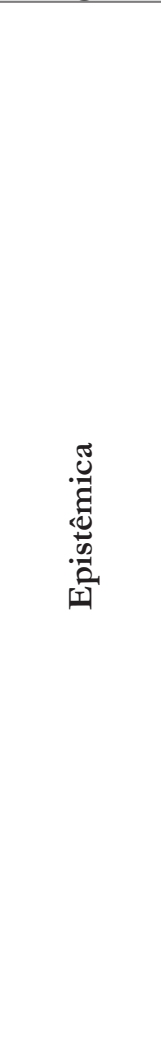 } & $\begin{array}{l}\text { Percepção do aprendizado pelas características da natureza } \\
\text { da informação/exigência da tarefa }\end{array}$ \\
\hline & $\begin{array}{l}\text { 11F - Tem que ter a teoria não é só a conta [para aprender]. } \\
25 \mathrm{AJ} \text { - Se for alguma coisa de conta, eu não vou aprender com a experiência. } \\
26 \mathrm{G}-\mathrm{E} \text { diferente pra certos tipos de matéria [aprender com experiências]. } \\
27 \mathrm{AJ}-\text { Depende muito [da matéria, para aprender com experiências]. } \\
43 \mathrm{MB} \text { - [...] pra matéria de humanas, por exemplo, história, tem que ler... mas pras } \\
\text { matérias mais exatas tem que buscar caminhos mais alternativos... [interiorização do } \\
\text { processo da aprendizagem]. } \\
135 \mathrm{AJ} \text { - [Resumo] Me ajuda muito, tipo no começo que era o primeiro bimestre, era mais fácil, acabava } \\
\text { a aula ia lá e fazia ... eu tenho muita dificuldade em história, tipo no segundo bimestre deixei } \\
\text { acumular, acabei não aprendendo nada porque fiz correndo a maioria. }\end{array}$ \\
\hline & Elaboração de esquemas e etapas para o aprendizado \\
\hline & $\begin{array}{l}\text { 13MB - Associar a alguma coisa próxima, senão fica tudo muito abstrato [para aprender]. } \\
51 \mathrm{G} \text { - Você esquece, depois você escuta a música você lembra... } \\
87 \mathrm{G} \text { - Eu lembro alguma coisa do cobertor... que a gente aprendeu na sétima série... que você } \\
\text { explicou numa aula e ela repetiu tudo e eu não lembro mesmo assim... [praticar]. } \\
116 \mathrm{G} \text { - Eu consigo [memorizar] tipo, no dia a dia, às vezes eu volto e penso: nossa, aconteceu } \\
\text { igual o professor falou, sei lá, também o céu quando eu vejo algum satélite, a lua... eu lembro, } \\
\text { nossa! Aprendi isso na aula de física, não que eu vá fazer algum cálculo, mas eu sei que } \\
\text { eu aprendi a matéria... } \\
1 \text { wG - Pra mim, atualmente, sei que aprendi física quando vejo um fenômeno do dia } \\
\text { a dia e sei a explicação física dele. Sei que existe como calcular a velocidade, o peso, o sentido, e } \\
\text { mesmo que a conta me traga dificuldades, ainda, eu entendo um pouco mais do porquê de as coisas serem } \\
\text { como são! É bem melhor do que apenas aceitar que elas são assim porque sim. } \\
206 \mathrm{I} \text { - Eu vejo... e tento... a males que vai pro bem [sobre resolver exercício]. }\end{array}$ \\
\hline
\end{tabular}


Quadro 1. continuação

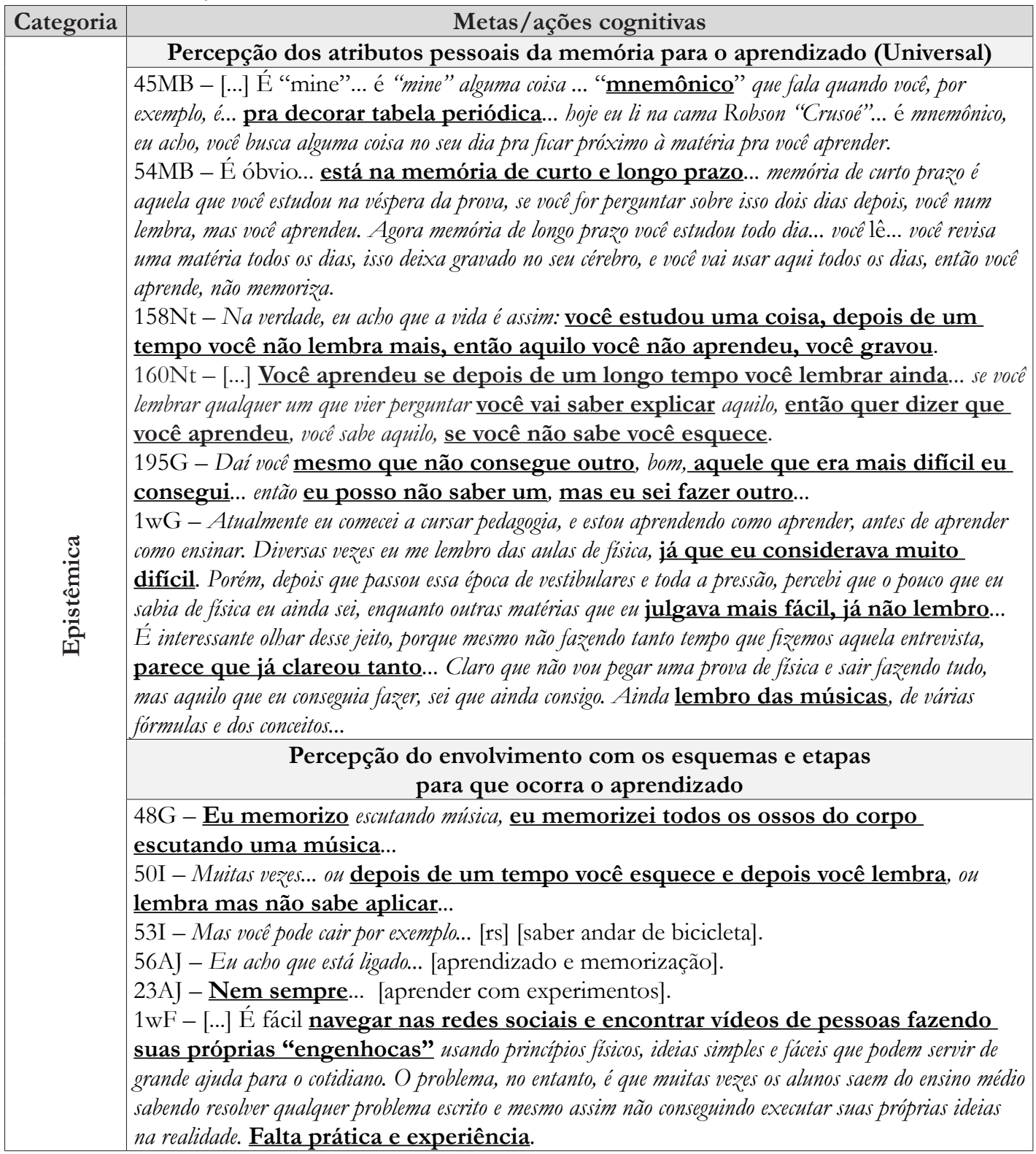

Fonte: elaborado pelos autores.

A categoria definida por "Epistêmica" tem em seu escopo o saber que existe independente do sujeito que aprende, observadas metacognitivamente por meio da reflexão na aprendizagem a respeito do que se declara ter aprendido, de acordo com as características da memória relevantes à aprendizagem. 
Para identificá-la consideramos diversos critérios que nos auxiliaram a interpretar os relatos, entre eles destacamos: o saber ou não saber determinado conteúdo ou realizar uma atividade; os elementos a serem lembrados para realização de uma tarefa; o reconhecimento do que é necessário ser feito e quais caminhos precisam ser seguidos para atingir determinada aprendizagem; a menção à associação do conhecimento a algo que efetive a aprendizagem; a remissão às situações vividas; a busca por "Estratagemas" para se alcançar o aprendizado; o reconhecimento do aprendizado, como uma experiência metacognitiva que envolve a variável da estratégia vinculada à avaliação; a mensuração das etapas e dos obstáculos encontrados; as lembranças, os esquecimentos, as percepções sobre saber ou não saber algo, num processo estratégico de simples avaliação; a percepção da própria memória e as crenças a respeito da mente humana; a necessidade de memorização e de realização de experimentos.

Por fim, consideramos que seu caráter epistêmico está intrinsecamente atrelado aos processos que envolvem o conhecimento cognitivo e metacognitivo da memória, seus processos e sua relação com objetos, pessoas e locais, de forma a possibilitar ou contribuir com a aprendizagem.

Quadro 2. Categoria pessoal e metas/ações cognitivas

\begin{tabular}{|c|c|}
\hline Categoria & Metas/ações cognitivas \\
\hline $\begin{array}{l}\text { ]ే } \\
0 \\
0 \\
0 \\
0 \\
0\end{array}$ & 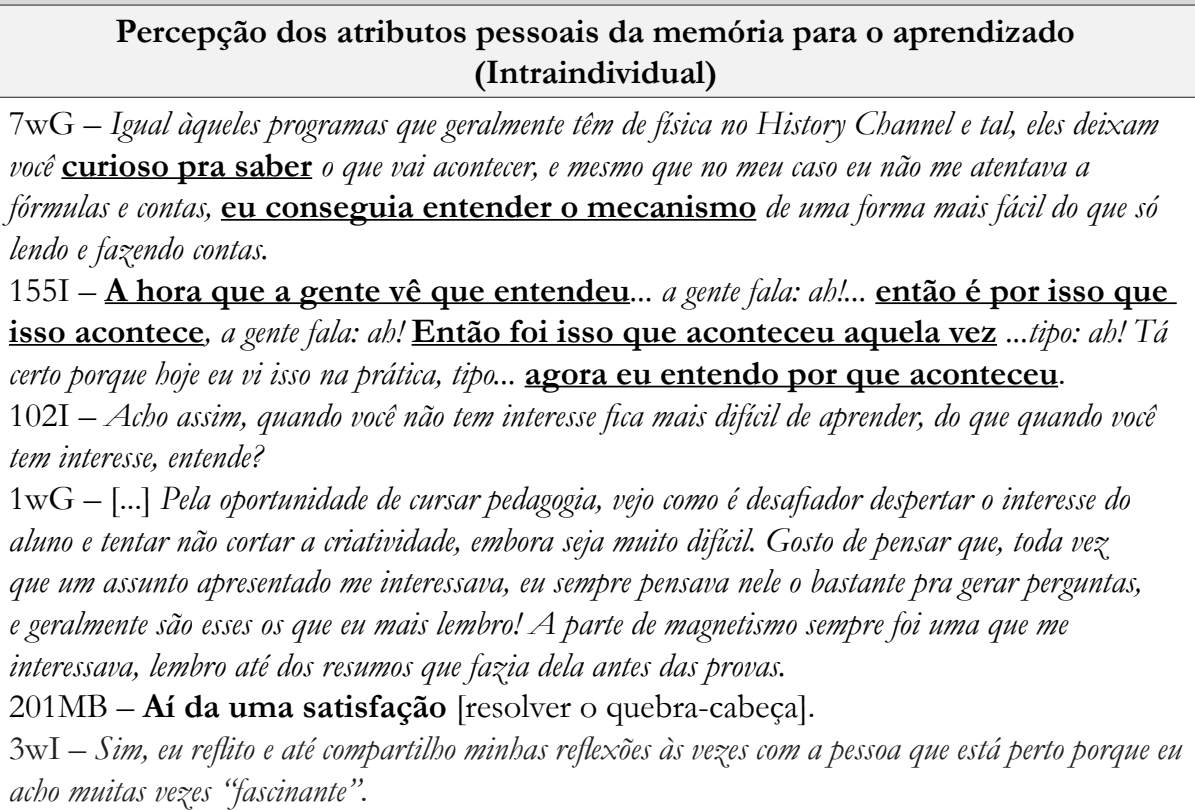 \\
\hline
\end{tabular}

Fonte: elaborado pelos autores.

Na categoria "Pessoal" definida pela relação com o saber, referenciando o saber enquanto objeto que faz sentido, objeto de desejo, de interesse, sendo, portanto, a reflexão sobre 
a aprendizagem a respeito do que o sujeito gosta de aprender, de acordo com as características da sua identidade relacionadas à aprendizagem de Física.

Para buscá-la nos depoimentos procuramos identificar falas que trouxessem indícios de planejamento, pois para planejar é necessário reconhecer se possui a habilidade necessária para a realização de determinada tarefa ou sentimentos demonstrados diante de determinado obstáculo, para então conseguir transpô-lo. Consideramos ainda que esta categoria está intimamente relacionada às características de como o indivíduo se sente diante da sua aprendizagem. Outros critérios assumidos nesta ocasião dizem respeito a momentos em que os estudantes discorrem sobre seus: entendimentos; interesses; emoções; demonstrando sensações de afetividade, excitação e outros sentimentos intimamente relacionados aos momentos de aprendizagem.

O que pudemos perceber é que a dimensão pessoal do aprender constitui-se no envolvimento com a experiência metacognitiva pertencente à variável da estratégia, como uma etapa de monitoramento ou avaliação. Assumida como um processo complexo que envolve a consciência de si, que gere algum tipo de sensação provocada pelo interesse ou gosto, na regulação do tempo e na modificação do lugar em que acontece o processo da aprendizagem.

Para a categoria "Social", amparada na experiência metacognitiva, partimos de pressupostos como: a percepção do próprio envolvimento com o aprendizado motivado pelo outro e para interagir com o mundo; a condição de o estudante nascer inscrito em uma sociedade já constituída, na qual a relação do aprender acontece por meio do contexto apresentado pelo mundo em que está inserido; a existência de valores externos ao estudante, propostos por uma comunidade que apresenta aspirações e expectativas com relação a este estudante que aprende.

Diante disso procuramos os destaques nos relatos que considerassem: os valores estabelecidos pela sociedade à qual ele pertence; as possibilidades de envolvimento com o outro, no que diz respeito a conversas, interações com professores, tutores, amigos e familiares, como também para estabelecer seu lugar na sociedade, no que se refere à escolha profissional, e todos os requisitos que esta escolha envolve.

Ficou evidente que a experiência metacognitiva provocada pelo social abarcou desde a comunidade, na qual o estudante está inserido no momento do seu nascimento, até o dia em que realizamos a entrevista com projeção para o fim de sua vida, perpassando por todas as etapas de desenvolvimento cognitivo e emocional. Outro fato constatado foi que a forma como o estudante valora sua aprendizagem diz respeito, diretamente, a como seu contato com o mundo foi e é constituído no seu dia a dia. Esses indícios foram resgatados durante a entrevista por meio das recordações e explicitações sobre seu processo de memorização, suas escolhas ou preferências a determinados conteúdos, suas afinidades com certas formas de ação relativas ao aprender.

$\mathrm{Na}$ sequência trazemos dois gráficos que retratam a acomodação da completude dos dados coletados e interpretados, ou seja, de posse de todas as falas categorizadas foi possível verificar as incidências em cada uma das categorias: epistêmica, pessoal e social (Gráfico 1), além de evidenciar por estudante suas características singulares relativas a cada uma delas (Gráfico 2). 
Quadro 3. Categoria social e metas/ações cognitivas

\begin{tabular}{|c|c|}
\hline Categoria & Metas/ações cognitivas \\
\hline \multirow{6}{*}{ 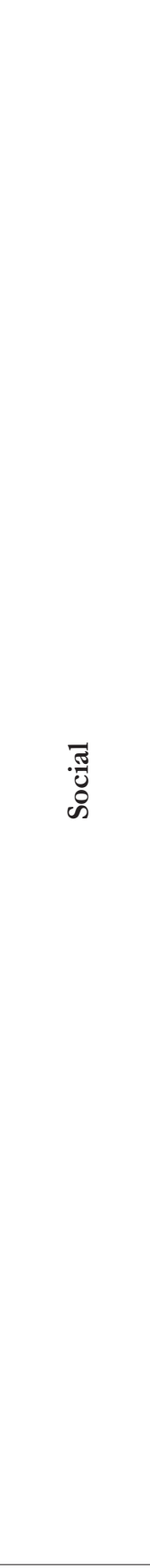 } & Percepção do envolvimento com o aprendizado motivado pelo outro \\
\hline & $\begin{array}{l}\text { 114Nt - Geralmente em Física, eu não sou muito boa não, acho que você já percebeu né? } \\
\text { 36MB - Internacionalizando as coisas... eu colocando pra mim mesmo... [aprender } \\
\text { sozinho]. } \\
\text { 149MB - Cada um tem o seu [processo de aprender]. } \\
\text { 269Nt - Principalmente numa matéria que você é ruim você consegue fazer um exercício,- } \\
\text { você se sente a pessoa mais inteligente do mundo. } \\
195 \mathrm{G} \text { - É que quando você consegue fazer o exercício, quando ele é muito difícil, você vê } \\
\text { que os outros têm dificuldade e você consegue... } \\
\text { 1wMB - Mesmo gostando eu sei que não é um assunto fácil para a maioria das pessoas, } \\
\text { pois demandam entender as coisas de uma outra forma. } \\
262 \mathrm{MB} \text { - [...] Você está usando o que como parâmetro? [ser mais inteligente] ... a escola? ... } \\
\text { esta pessoa pode ser mais inteligente naquilo... mas tem tantas pessoas que falam que sabem } \\
\text { fazer tantas coisas e não são cobradas delas, por isso que acho que... não devia ser certo ficar } \\
\text { chamando um ou outro de inteligente. }\end{array}$ \\
\hline & Percepção do envolvimento com o aprendizado para interagir com o mundo \\
\hline & $\begin{array}{l}\text { 32MB - Em termos... [aprender sozinho]. } \\
283 \mathrm{Nt} \text { - Porque essa pessoa já sabe o assunto e transmite pra gente de uma forma mais fácil de } \\
\text { compreender. } \\
285 \mathrm{G} \text { - Tirar as dúvidas [aprender com o outro]. } \\
289 \mathrm{AJ} \text { - Mas você que já sabe, você vai dar o caminho pra gente aprender [aprender com o } \\
\text { outro]. } \\
290 \mathrm{I} \text { - Vai falar as palavras certas, entende... [sobre aprender com o outro]. } \\
292 \mathrm{I} \text { - Não sei... [as palavras certas]. }\end{array}$ \\
\hline & Percepção dos atributos pessoais da memória para o aprendizado (Interindividual) \\
\hline & $\begin{array}{l}170 \mathrm{G} \text { - Mas eu acessei um acontecimento na minha vida que quando eu fui na aula da } \\
\text { Denise tinha acontecido uma coisa horrivel dai eu tava chorando e eu num... então foi essa matéria... } \\
\text { 304G - } \text { As palavras certas, tipo, você já viu isso na sua vida, agora você já sabe o } \\
\text { que é... } \\
306 \mathrm{G} \text { - Sim, agora você já sabe o que acontece, quando você vê aquilo você já sabe o que } \\
\text { está acontecendo, acho que é isso. } \\
1 \mathrm{wI}-[. . .] \text { E eu aprendi bastante a gostar de física por relacionar a acontecimentos que acontecem } \\
\text { diariamente com a gente! Acho que esses tipos de matérias que você consegue pôr no cotidiano ficam } \\
\text { mais fáceis de se aprenderem e se entenderem. } \\
1 \mathrm{wNt} \text { - Como sabe a física nunca foi muito minha amiga e eu também não me esforçava para } \\
\text { aprender ela até que um dia, como te contei, percebi a falta que toda matéria perdida por eu não prestar } \\
\text { atenção estava me fazendo. Infelizmente ou felizmente me toquei disso e passei a levar os estudos } \\
\text { a sério. Com toda certeza física nunca foi minha matéria preferida, assim como qualquer } \\
\text { matéria que inclua exatas, mas era na que eu mais me esforçava especialmente por isso e até minha mãe } \\
\text { percebia... } \\
1 \mathrm{wF} \text { - [...] Porque, ao menos na minha opinião, é um grande desperdício aprender Física unicamente } \\
\text { através de exercícios e aulas teóricas sendo que o seu campo de atuação é justamente a realidade. }\end{array}$ \\
\hline
\end{tabular}

Fonte: elaborado pelos autores. 
Gráfico 1. Processo Metacognitivo do Grupo

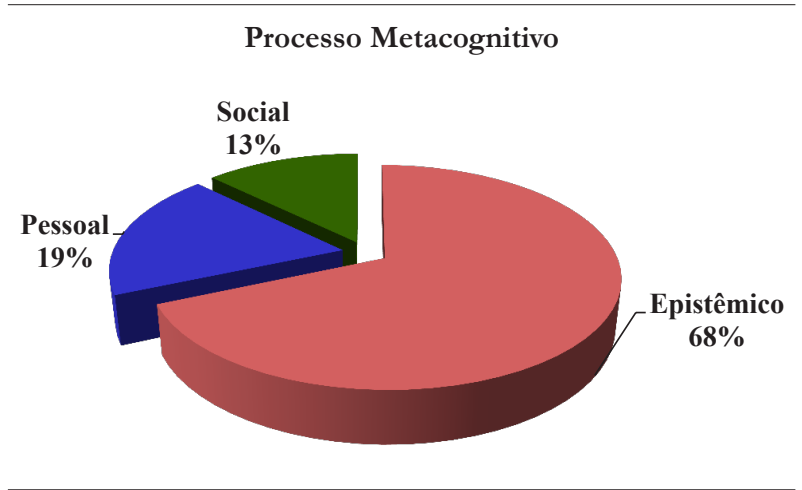

Fonte: elaborado pelos autores.

Chegamos a esta representação a partir do momento em que quantificamos todos os depoimentos (266 excertos analisados): 182 Epistêmicos, 50 Pessoais e 34 Sociais, o que nos levou às porcentagens aproximadas apresentadas no Gráfico 1.

Como podemos perceber a maior ocorrência foi na categoria Epistêmica, em virtude de expressarem-se com maior facilidade sobre o que percebem saber ou não saber, e demonstrarem certa dificuldade de verbalização quanto ao que sentem e valoram (percepções relacionadas às categorias Pessoal e Social).

$\mathrm{Na}$ continuidade descrevemos, em resumo, diversos detalhes sobre o processo interpretativo da entrevista focando nas categorias Epistêmica, Pessoal e Social.

Por meio das colocações dos estudantes com relação à categoria Epistêmica fomos levados a concluir que eles conseguem, com certa clareza: indicar o que é preciso para aprender os conteúdos de Física; as diferenças entre as demandas desta e de outras disciplinas; o nível de dificuldade encontrada no processo de aprendizagem de Física (22 relatos destacam situações pontuais sobre a Física, entre elas as fórmulas); quanto à elaboração de esquemas e etapas para o aprendizado de Física, destacaram a necessidade de contextualizar ou associar a algo conhecido; quanto às estratégias - planos e táticas, perfazendo um total de 30 relatos - indicaram a leitura, a escrita, o grifo, a visualização, as explicações, a resolução de exercícios; com relação à constatação de que aprenderam temos 37 relatos em que revelam essa percepção, contudo não conseguem descrevê-la claramente, justificando que há uma naturalidade nesse reconhecimento; sobre o processo de memorização (36 excertos) descrevem situações a respeito da memória de curto e longo prazo, o acúmulo de experiências, o raciocínio lógico relacionado com o processo de aprendizagem da Matemática, comparações com a resolução de quebra-cabeça (em que cada peça auxilia na identificação da outra parte ou do todo), a memorização de uma fórmula não "significa o aprendizado" de sua utilização; com relação à resolução de exercícios argumentam que por meio deles é possível verificar uma aprendizagem "completa" ou "parcial" relacionada 
diretamente ao nível de dificuldade na resolução dos mesmos; no que diz respeito às atividades experimentais de Física realizadas na escola, argumentam que essas atividades práticas dão "sentido ao aprendizado", tornando menos abstratos os conceitos e possibilitando a memorização.

Os depoimentos que foram acomodados e organizados na categoria Pessoal carregam características diferentes dos elencados anteriormente (categoria Epistêmica), pois eles tratam do autoconhecimento e de reflexão sobre si, destacando particularidades e afinidades na mobilização dos processos cognitivos.

Diante de uma leitura contínua desses relatos foi possível evidenciar algumas caracterizações, entre as quais destacamos: a importância do entendimento no processo da aprendizagem, afirmando que essa consciência sobre o sentimento de entendimento promove a reorganização do conhecimento e proporciona satisfação; o interesse por determinado conteúdo, promovendo a facilidade no aprendizado do mesmo; o monitoramento da aprendizagem, vinculado a emoções tais como desespero, satisfação, frustração, calor no coração, emudecimento (31 relatos).

A relação Social do processo metacognitivo (categoria menos presente nos relatos) mostra suas evidências por meio das interações relativas ao outro e com o mundo. Essa "necessidade do outro" para o processo de aprendizagem fica explicitada na fala por meio de expressões como: "aprender sozinho é difícil, é quase impossivel”; "ela usa as palavras corretas, por isso eu entendo"; "ela consegue acionar a minha mente"; "pessoas não tão experientes nesse assunto vão entender", nesse último exemplo quando se refere a ter outro olhar diante de um obstáculo e apresentar um caminho para sanar as dúvidas e incompreensões.

Existem remissões a situações que envolvem familiares - ele conta - "percebi que ao explicar o fenômeno para ele [pessoa da família] eu sabia mais sobre o assunto do que imaginava saber"; relativas a lembranças de determinadas aulas, de explicações recebidas de colegas de classe e professores, de conteúdos estudados, de relações estabelecidas que tiveram diálogos triviais e situações cotidianas como deflagradoras de assuntos relacionados à Física.

No que diz respeito às interações com o mundo, os excertos destacam inúmeros "casos" que pouco a pouco os estudantes vão recuperando em suas lembranças e os outros depoentes que participaram das entrevistas acenam com a cabeça indicando consentimento, manifestam-se com um sinal de positivo, afirmam "comigo também foi assim”. Entre essas declarações selecionamos algumas: "a matéria ganha outro sentido ao adquirir uso prático", quando visualizaram na internet uma "engenhoca" que utilizava os princípios físicos para funcionar; "esses programas de TV ou documentários atiçam meu interesse em aprender", elencando uma diversidade de livros, de autores e atores, de séries televisivas e programas que remetem à compreensão de conceitos até então não aprendidos, promovendo o entendimento e a reorganização "mental” do que já haviam estudado.

Destacam ainda que, pela não obrigatoriedade em aprender, esses momentos passam a contribuir com o aclaramento das ideias sobre o assunto. Essas situações ampliam a curiosidade a respeito do tema, levando-os a buscarem por mais e mais informações, fatos que promovem maior interação com o mundo mobilizando dispositivos do processo metacognitivo.

A seguir apresentamos no Gráfico 2 a acomodação dos excertos em suas categorias por estudante, o que reforça a presença da categoria Epistêmica. 
Gráfico 2. Processo Metacognitivo por Estudante

Categoria Epistêmica — Categoria Pessoal — Categoria Social

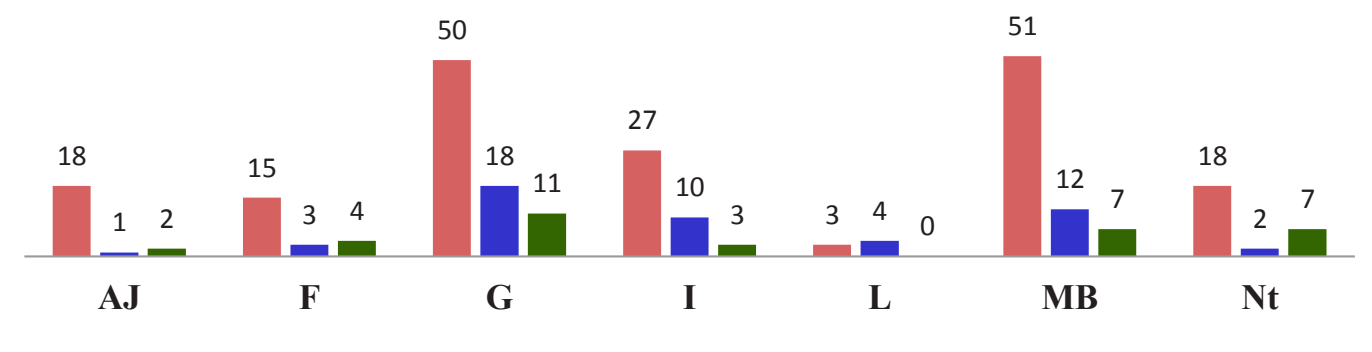

Fonte: elaborado pelos autores.

\section{Considerações finais}

Diante do exposto, podemos agora retomar nossos questionamentos investigativos, procurando sistematizar os resultados proporcionados por esta pesquisa. Nossa proposição primária foi identificar e analisar as percepções e reflexões de estudantes de Ensino Médio no processo metacognitivo da aprendizagem em Física. Para tal coletamos os dados por meio de uma entrevista coletiva, em que os estudantes narraram sobre seus processos de aprendizagem de forma reflexiva, o que nos permitiu evidenciar certas percepções.

Para realizar a análise dessas percepções relativas ao processo metacognitivo, fizemos um percurso teórico sobre os temas: aprendizagem, relações com o saber, metacognição (alguns extratos resumidos desses estudos foram apresentados neste artigo). Por meio desses estudos foi possível organizar subsídios teóricos que permitissem compreender a composição do processo metacognitivo e relacioná-los às relações com o saber. Ao optarmos por determinada categorização obtivemos alguns avanços na interpretação dos processos metacognitivos envolvidos na aprendizagem, partindo da aceitação de que a dimensão epistêmica era um fato, e por isso seria a mais destacada, buscando pela evidenciação das dimensões pessoal e social.

A partir das falas e das expressões manifestas durante a entrevista e complementadas posteriormente, tornou-se possível afirmar que os estudantes depoentes conseguiam "perceber" sua aprendizagem: diferenciando o aprendizado entre disciplinas e conteúdos; relatando os diferentes níveis de dificuldade para a aprendizagem de conceitos teóricos e práticos; apontando diferenças e dificuldades encontradas nas etapas de resolução das atividades.

Apesar de nossas conjecturas a respeito da maior presença de percepções do processo metacognitivo Epistêmico - os depoimentos corroboraram com elas - não que sejam mais importantes, todavia, devido ao que se encontra estabelecido no ambiente escolar, tornam-se de fácil verbalização quando a indagação é sobre o processo de aprendizagem.

Os atributos pessoais começaram a ser ventilados nas narrativas que focaram o processo de memorização e sua relação com a aprendizagem, a busca por esclarecer tal processo levou a uma sistematização de como faziam para aprender Física e, sobretudo, como se reconhecem como aprendizes de Física, uns em relação aos outros. 
Nesses relatos de reconhecimentos e desconhecimentos, emergiram espontaneamente as diferenças, reconstituindo falas e gestos de concordância e de discordância, relativos à esquematização verbalizada sobre o processo de aprendizagem, surgindo divergências com relação ao envolvimento com as estratégias, esquemas e etapas da aprendizagem. Foram nesses momentos - trazidos durante a entrevista coletiva - que diversos estudantes sentiram a necessidade de explicar (solicitando uma intervenção na fala de outro depoente) como compreendiam suas aprendizagens, todavia os exemplos perpassam somente por elaborações práticas, entre elas citamos essa interação com o ato de ler: a leitura, a leitura em voz alta, a explicação do texto lido para si mesmo, a explicação do texto lido para outra pessoa, mostrando-se as particularidades que compõem cada etapa do aprendizado.

Com referência aos atributos sociais - considerando o outro - ao final da discussão, mesmo tendo alguns deles (inicialmente) se posicionado a respeito de que o aprender é um processo particular e solitário, em determinado momento da entrevista, concordaram com a necessidade da presença de alguém que soubesse o conteúdo para explicar, solucionar dúvidas e possibilitar situações em que a temática (a ser aprendida) estivesse na pauta. Essas manifestações, compartilhadas pelo grupo, obtiveram ainda alguns acréscimos de detalhes: a necessidade da utilização de uma linguagem acessível e de fácil compreensão.

Ainda com relação a esta dimensão social do aprender - agora tendo como foco o mundo -, cabe revelar que as inserções relativas a ela intensificaram-se durante o processo de devolutiva da entrevista, para que complementassem ou revisassem o que haviam relatado. Depois de lerem a transcrição individualmente inseriram afirmativas enfatizando que é mais tranquilo, prazeroso e interessante - e até um lazer - aprender Física por meio de programas de televisão, séries televisivas, vídeos na internet, filmes diversos, visitação a parques de diversão, conversas informais sobre fenômenos físicos naturais, do que na escola, focalizando especificamente nas exigências com relação à memorização do conteúdo e das fórmulas.

Por fim, diante do exposto por esses estudantes, pudemos compreender que os processos metacognitivos epistêmicos, pessoais e sociais são percebidos e explorados por eles, durante a aprendizagem da Física, possibilitando afirmar que o saber, o sentir e o valorar estão imbricados nas situações reflexivas do processo metacognitivo. Além disso, estão relacionados, diretamente, com a autorregulação que envolve o reconhecimento e planejamento das ações voltadas para a aprendizagem, o monitoramento desse processo, sua avaliação e a realimentação do todo mediante as reflexões que emergem do contato com o outro e com o mundo.

\section{Agradecimentos}

Os autores agradecem o auxílio do Conselho Nacional de Desenvolvimento Científico e Tecnológico (CNPq) e da Fundação Araucária. 


\section{Referências}

ARRUDA, S. M.; LIMA, J. P. C.; PASSOS, M. M. Um novo instrumento para a análise da ação do professor em sala de aula. Revista Brasileira de Pesquisa em Educação em Ciências, Belo Horizonte, v. 11, n. 2, p. 139-160, 2011.

CHARLOT, B. Da relação com o saber: elementos para uma teoria. Porto Alegre: Artes Médicas, 2000.

FLAVELL, J. H. First discussant's comments: what is memory development the development of? Human Development, Basel, v. 14, n. 4, p. 272-278, 1971. Disponível em: <https:/ / doi.org/10.1159/000271221>. Acesso em: 18 maio 2018.

FLAVELL, J. H. Metacognition and cognitive monitoring: a new area of cognitive-developmental inquiry. American Psychologist, Washington, v. 34, n. 10, p. 906, 1979. Disponível em: <http://dx.doi.org/10.1037/0003-066X.34.10.906>. Acesso em: 18 maio 2018.

FLAVELL, J. H.; WELLMAN, H. M. Metamemory. In: ANNUAL MEETING OF THE AMERICAN PSYCHOLOGICAL ASSOCIATION, 83., Chicago, 1975. Bethesda: National Institute of Child Health and Human Development, 1975. p. 1-66. Disponível em: <https:// files.eric.ed.gov/fulltext/ED115405.pdf>. Acesso em: 18 maio 2018.

FLICK, U. Introdução à pesquisa qualitativa. 3. ed. Porto Alegre: Artmed, 2009.

ILLERIS, K. Uma compreensão abrangente sobre a aprendizagem humana. In: ILLERIS, R. (Org.). Teorias contemporâneas da aprendizagem. Porto Alegre: Penso, 2013. p. 15-30.

MORAES, R.; GALIAZZI, M. C. Análise textual discursiva. Ijuí: Unijuí, 2011.

PETERSON, P.; BAKER, E.; McGAW, B. (Ed.).International encyclopedia of education. 3rd. ed. Oxford: Elsevier, 2010.

SZYMANSKI, H.; ALMEIDA, L. R.; PRANDINI, R. C. A. R. A entrevista da pesquisa em educação: a prática reflexiva. Brasília: Liber, 2008.

TUNES, E.; BARTHOLO, R. Dois sentidos do aprender. In: MARTINEZ, A. M. E.;

TACCA, M. C. R. V. A complexidade da aprendizagem. São Paulo: Alínea, 2009. p. 11-29.

Artigo recebido em 03/03/2017. Aceito em 21/10/2017.

Contato: UEL, Departamento de Física, Campus Universitário,

Rodovia Celso Garcia Cid (Pr. 445), Km 380, Londrina, PR, CEP

86061-060, Brasil. 